\title{
Analyzing Policy Formulation and Implementation: The Case of Ethiopian National Youth Policy
}

\author{
Esubalew Aman \\ Lecturer at Department of Sociology, Wolkite University, Ethiopia
}

\begin{abstract}
This article aims to critically analyze policy formulation and implementation of Ethiopian Youth policy. A qualitative approach was employed to collect and analyze the data needed to address the aforementioned objectives. Accordingly, the study has employed document analysis to analyze policy formulation process. Besides, key informant interviews were held with two officers working at Central Gondar zonal office to analyze policy implementation. Accordingly, the study has found the policy document as professionally designed. However, the study shows some hitch in formulating the policy such as; while stating vision and goal of the policy, the policy document fails to include reference of time parameter as to when to achieve the stated goal of the policy. Moreover, the study found the policy document ignoring to discuss the importance and inclusion of youth participation in decision making process of the policy implementation. Furthermore, the policy implementation analysis focuses on themes like enabling legislation and regulations, organizational structure, organizational process, and program performance.
\end{abstract}

Keywords: Ethiopian Youth Policy, Policy Analysis, Policy Formulation, and Policy Implementation.

DOI: $10.7176 / \mathrm{PPAR} / 11-3-01$

Publication date: April $30^{\text {th }} 2021$

\section{Introduction}

There is no agreement upon definition on the term youth across countries of the world. The UN (United Nations) defines youth as individual aged between 15 to 24 years old. The African Union defines youth as individual aged between 15 to 35 years old. Besides, Ethiopian Youth Policy defines youth as to include part of the society who are between 15-29 years (NYPE, 2004).

The Ethiopian population is estimated to be more than 104 million people, among whom more than $28 \%$ are young aged between 15-29 years. The demographic significance of this young people is increasingly taking center stage in discussions to achieve socio-economic development agenda of the country. For instance, five of the eight Millennium Development Goals (MDGs) speak to improving the situation of young people (The United Nations Economic Commission for Africa (UNECA, 2009) \& United Nations Population Fund (UNFPA, 2013)). Youth has been at the center point on the struggle for democracy and good governance in Ethiopia. As ancient and modern Ethiopian history told us there were different revolutions at different time in the country, we have been observed the role of youth in the democratization process of the country. In Ethiopia youth has been at the center of democratic struggle.

Nonetheless, high unemployment rate, scarcity of recreational youth centers, lack of quality education, and lack of suitable environment for youths remains a central issue in Ethiopia, driving youth to violence and crime, substance addiction, hopeless and be prone to HIV/AIDS. To this effect, uprisings of young people in Ethiopia are clear manifestations of youth claims against unemployment, socioeconomic marginalization, unsound economic and social policies, corrupt governments and exclusion, political dictatorship and denial of basic rights (NYPE, 2004). Therefore, the need to act now and develop a strategy emphasized on employment, entrepreneurship, education, political inclusion of the youth is important. Moreover, quality schools, intelligent government policies, nurturing homes, and community environments help the youth to participate and claim their destiny. Young people are also keen on democracy's promise. They want political equality, they want social and economic inclusion and opportunity and they want accountable rulers.

To this end, a general knowledge and understanding of the present day youth and youth policy are of paramount importance for researchers, policy makers, practitioners and others who work for and with young people. Against this background, this paper attempts to critically analyze the National Youth Policy of Ethiopia. To do this, the paper aims to analyze the policy formulation and its overall implementation at nationwide and Central Gondar zone, Ethiopia.

Since youth policy falls within the broader parameters of the social policy, it would be fitting to use the six basic elements of a value critical appraisal of social policy and programs, to analyze policy formulation of the National Youth Policy of Ethiopia. Besides, Copeland and Wexler (1995) implementation framework analysis was employed to analyse the policy implantation process.

\section{Objective of the Study}

Mainly this study attempts to analyze the National Youth Policy of Ethiopia. Along with this, the study has 
specifically aimed to:

$>$ Analyze the policy formulation process by giving a due emphasis on value base criteria to make judgments on the goodness, fitness, and appropriateness of a policy.

$>$ Analyze the policy implementation in line with policy action implemented to address recognized policy problems.

\section{Methodology}

The study aims to analyze the formulation and implementation process of Ethiopian Youth Policy at country level in general and Central Gondar Zone in particular. To this effect, the study has employed document analysis for investigating the nature of a policy document in order to look at both what lies behind it and within it. Moreover, the study has employed document analysis along with key informant interviews to analyze the policy implementation process at both country level and Central Gondar zone. Key informants were selected based on purposive sampling technique.

In the course of conducting interviews, the researcher has recognized ethical consideration of conducting research. In line with this, the informants were asked for their consent to participate in the study; and were invited to share their opinions and experiences after the researcher had built mutual trust with the participants in the belief that the information will not be used in an inappropriate or harmful manner. The participants were informed that they have rights to refuse participating in the study at any time and skip any particular question they might not want to answer.

Besides, the study has employed two different types of analytical framework to address central issues of the study. On the one hand, Value Critical Policy Analysis Framework was employed to analyze the policy formulation process. On the other hand, Copeland and Wexler (1995) Implementation Analysis Framework was employed to analyse the policy implementation process. The overview of these analysis frameworks will be discussed as follows.

\subsection{Value Critical Policy Analysis Framework}

Value Critical Approach is used to analyze the policy formulation process. Value critical approach is selected as analysis framework for policy formulation since it is important to critically evaluate all parts of a policy and how they fit together as a whole. Besides, based on a value based criteria it will help the policy analyst to make judgments on the goodness, fitness, and appropriateness of a given policy. Hence, value critical approach seeks to uncover shortcomings, inconsistencies in logic, and ambiguities in the everyday program operations (Chambers \& Wede, 2005).

As described by Chambers and Bonk (2013), in order to apply a value critical policy analysis approach there are six-policy elements which form the cornerstone of every policy and it is these policy elements on which the practical social policy analyst ultimately base judgments about a policy or program. Therefore, for the case of this study each of the six evaluation criteria were selected. These criteria include:

A. Mission, goals, and objectives

B. Forms of benefits or services delivered

C. Entitlement (eligibility) rules

D. Administrative or organizational structure for service delivery

E. Financing method and

F. Interactions among the foregoing element

\subsection{Copeland and Wexler Implementation Framework Analysis}

Copeland and Wexler (1995) implementation framework analysis is used to analyse the policy implementation process. Studying policy implementation help us: to address the influence of state bureaucratic factors on welfare policy implementation; to explain variation in policy implementation within and across states; to demonstrate the interrelationship between the policy implementation process and program performance; and to assess the extent of intended change produced in the larger society by a program. Moreover, implementation study attempt to explain the implementation process, examine the extent to which programmatic goals were satisfied, and describe how well the policy performed, given the way in which the state compiled with the federal mandate.

Copeland and Wexler (1995) implementation framework analysis is used to analyse the implementation of the policy. The framework incorporates the following domain to analyse the implementation of a given social policy:

A. Enabling Legislation

B. Federal Regulations

C. Organizational Structure

D. Organizational Process

E. Program Performance 


\subsection{Data Sources and Instruments for Data Collection}

The study was conducted based on both secondary and primary data sources. On the one hand, secondary data were used to analyze policy formulation. Therefore, previous studies, articles, institutional documents, journals, websites and other written sources were critically reviewed. On the other hand, key informant interviews were conducted to collect primary data and analyze policy implementation process at zonal level.

\section{Data Analysis}

Part I:

\subsection{Analysis of Ethiopian Youth Policy Formulation}

In order to analyze the formulation of the policy, the study has employed Value Critical Approach.

\subsubsection{Goals and Objectives of the National Youth Policy of Ethiopia}

According to Chambers and Bonk (2013), a goal conveys a clear idea of what the program or policy wishes to accomplish. All elements of a policy analysis are evaluated on the basis of their contribution to the goals and objectives. Table 1 below shows an overview of the basic elements, types of the basic elements and evaluation criteria used to analyze policy goals and objectives.

Table 1: Evaluation Criteria for Analyzing Policy Goals and Objectives

\begin{tabular}{|c|c|c|}
\hline $\begin{array}{l}\text { Basic Policy } \\
\text { Element }\end{array}$ & Types & Evaluation criteria \\
\hline $\begin{array}{l}\text { Mission, } \\
\text { Goals, and } \\
\text { Objectives }\end{array}$ & $\begin{array}{l}\text { 1. Principles Or } \\
\text { Purpose } \\
\text { 2. Long } \\
\text { Term/Short Term } \\
\text { 3. Manifest/Latent }\end{array}$ & $\begin{array}{l}\text { 1. Criteria Specific To Goals And Objectives } \\
\quad \text { Not Just Service Delivery But End Product } \\
\text { Clarity, Measurability, Manipulability } \\
\text { 2. Implications Of Goals And Objectives For Adequacy, Equity, And } \\
\text { Efficiency } \\
\text { 3. Fit Of Goals And Objectives With The Social Problem Analysis: } \\
\text { Problem Definition And Variables (Consequences) In Causal Analysis }\end{array}$ \\
\hline
\end{tabular}

Source: Rein, 1983 Cited In Chambers \& Wedel (2005)

The intended outcomes of the national youth policy of Ethiopia are to create an empowered young generation with democratic outlook and ideals, equipped with knowledge and professional skills, are organized and built on ethical integrity. From the participatory and beneficiary standpoints, the national youth policy of Ethiopia was founded on the following four basic principles. (1) Ensuring youth to be active participants and beneficiaries from democratization and economic development activities; (2) Bringing about unity through recognition and respect of diversity; (3) Organized freely and make coordinated move to protect rights and interests; and (4) Capacity building. Moreover, a wide range of policy priority areas of action are identified, including democracy and good governance, health, education and training, as well as culture, sport and entertainment (NYPE, 2004).

The evaluation criteria for analyzing mission, goal and objectives of the policy, as described by Rein, 1983 Cited in Chambers \& Wedel, 2005, considers issues related to clarity, measurability and manipulability of the elements. In line with this, the social problem and situation of youths in the country has been markedly stated. Besides, the objective of the policy was clearly defined in a measureable and flexible way. Even though, the policy document states vision and goal of the policy on, it fails to give reference of time parameter as to when to achieve the stated goal of the policy.

\subsubsection{Form of Benefits and Services Delivered}

The policy has promised to offer different forms of benefits and services for Ethiopian youth, categorized under four broad domains: (1) Access to basic health facilities, (2) Access to education, (3) Employment creation, and (4) provided with professional, technical and leadership capacity building.

The evaluation criteria for analyzing form of benefits and service delivery of the policy, as described by Rein, 1983 Cited in Chambers \& Wedel, 2005, considers issues related to cost effectiveness, fitness to the social problem analysis, and its implication to the issue of adequacy, equity and efficiency (see table 2 below). 
Table 2: Evaluation Criteria for analyzing forms of Benefit and Service Delivery

\begin{tabular}{ll}
\hline $\begin{array}{l}\text { Basic Policy } \\
\text { Element }\end{array}$ & Types \\
\hline $\begin{array}{l}\text { Forms of } \\
\text { Benefits And }\end{array}$ & $\begin{array}{l}\text { 1. Personal Social Services } \\
\text { Services }\end{array}$ \\
& $\begin{array}{l}\text { 2. "Hard Benefits": Cash, Goods, } \\
\text { Commodities }\end{array}$ \\
& 3. Positive Discrimination \\
& 4. Credits/Vouchers \\
& 5. Subsidies \\
& 6. Government Loan Guarantees \\
& 7. Protective Regulations \\
& 8. Supervision Of Deviance \\
& 9. Power Over Decisions
\end{tabular}

Evaluation criteria

1. Criteria Specific To Benefits And Services

$>$ Stigmatization

$>$ Target Efficiency

$>$ Cost-Effectiveness

$>$ Substitutability

$>$ Consumer Sovereignty

$>$ Trade-Offs

$>$ Coerciveness/Intrusiveness

$>$ Complexity And Cost Of Administration

$>$ Adaptability Across Users

$>$ Political Risk

2. Implications Of Benefit/Service For Adequacy, Equity, And Efficiency

3. Fit Of Benefit/Service Form With The Social Problem Analysis

Source: Rein, 1983 Cited In Chambers \& Wedel (2005)

Considering the above-mentioned criteria, the form of benefits and service deliveries are in line with the social problem analysis. Since, the policy is implemented at different level (i.e. federal, regional, zonal, and kebele level); the issue of cost effectiveness, adequacy, equity and efficiency could be managed and secured at best.

\subsubsection{Entitlement or Eligibility Rules}

Eligibility rules determine; who gets what? How much? and under what conditions? Therefore, policy document is an important source of eligibility for this. As it is stated on the national youth policy of Ethiopia, part of the society who are between 15-29 years are entitled to get an equal opportunity in building democracy, promoting good governance and socio-economic development of the country, and get benefits from the result fairly.

The evaluation criteria for analyzing entitlement/eligibility rules of the policy, as described by Rein, 1983 Cited in Chambers \& Wedel, 2005, considers issues related to stigma/alienation, specification of the target group and the overall implication on adequacy, equity, and efficiency (see table 3 below).

Table 3: Evaluation Criteria for Analyzing Eligibility Rules.

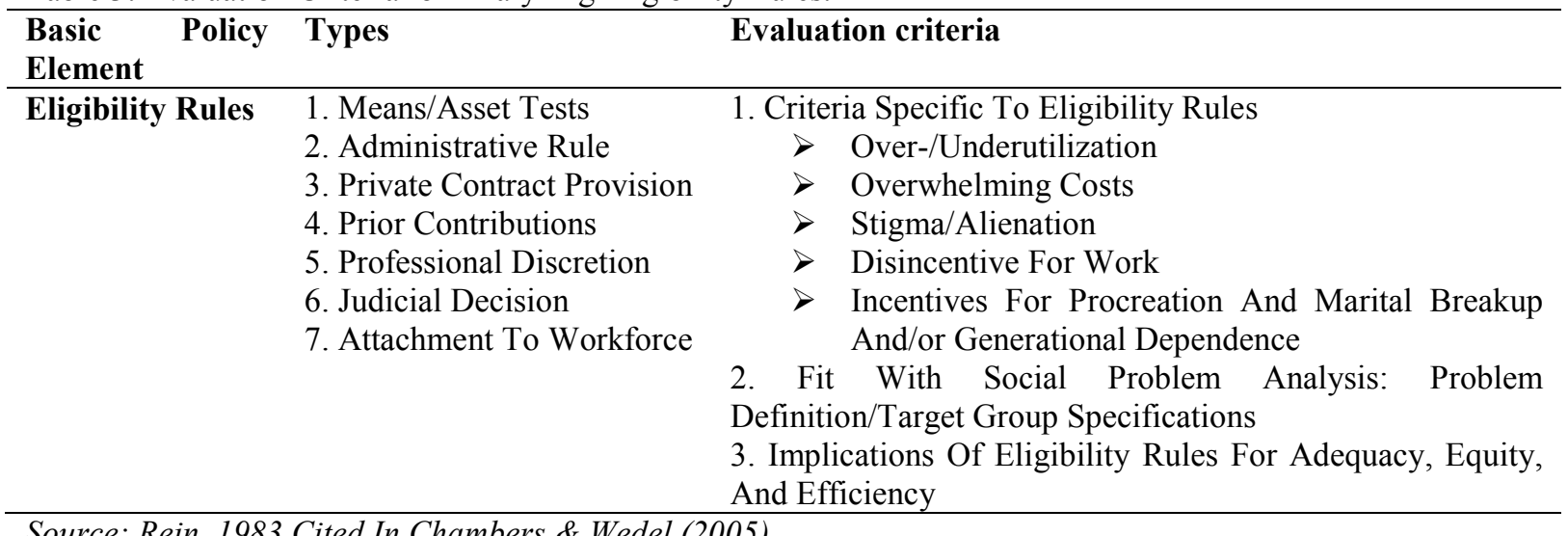

Source: Rein, 1983 Cited In Chambers \& Wedel (2005)

Based on these criteria, the policy document has clearly specified which segment of the population has to be considered in the policy without stigmatizing and favored to any groups. With this regard I found the policy document as being adequate and efficient.

\subsubsection{Administration and Service Delivery}

Service delivery is the how of social policy analysis. Rein, 1983 Cited in Chambers \& Wedel, 2005, offer several criteria specifically for evaluating service-delivery systems. For example, benefits and services should be (a) integrated and continuous; (b) accessible to clients and beneficiaries; and (c) the organization delivering them should be accountable for its actions and decisions (see table 4 below). Ensuring youth to be active participants and beneficiaries from democratization and economic development activities of the country is a core principle of the policy that introduces participatory and beneficiary approach intervention for Ethiopian youth. 
Table 4: Evaluation Criteria for Analyzing Administration and Service Delivery.

\begin{tabular}{|c|c|c|c|}
\hline \multicolumn{2}{|c|}{ Basic Policy Element } & Types & Evaluation criteria \\
\hline \multirow{12}{*}{$\begin{array}{l}\text { Administration } \\
\text { Service Delivery }\end{array}$} & And & 1. Centralization & 1. Evaluation Criteria Specific \\
\hline & & 2. Federation & Administration/Service Delivery \\
\hline & & 3. Case Management & $>$ Has An Articulate Program/Policy \\
\hline & & 4. Referral Agency & Design \\
\hline & & 5. Indigenous Worker Staffing & $>$ Integration/Continuity \\
\hline & & 6. Racially Oriented Agencies & $>$ Accessibility \\
\hline & & 7. Administrative Fair Hearing & $>$ Accountability \\
\hline & & 8. Due Process Protections For & $>$ Client/Consumer Empowerment \\
\hline & & Clients' Procedural Rights & $>$ Consumer Participation In Decision \\
\hline & & 9. Citizen Participation & Making \\
\hline & & & $\begin{array}{l}\text { Coping With Racial, Gender, And } \\
\text { Ethnic Diversity }\end{array}$ \\
\hline & & & $\begin{array}{l}\text { 2. Fit With Social Problem Analysis } \\
\text { 3. Implications For Adequacy, Equity, And } \\
\text { Efficiency }\end{array}$ \\
\hline
\end{tabular}

Source: Rein, 1983 Cited In Chambers \& Wedel (2005)

In the process of implementing the policy; various strategies, short, medium and long term programs and manuals are going to be implemented and put into action. In line with this the Ministry of Youth, Sports and Culture and, likewise, youth bureaus established in the regions have the responsibility to coordinate, integrate and evaluate the policy implementation, and assess youth participation and benefit and indicate the directions that should be undertaken prospectively. In view of this, the policy was formulated in an integrated way with a clear hierarchical system showing organizational accountability of their actions and decisions.

Activities that enhance the implementation capacity and youth participation and benefits shall be mainstreamed in the strategic plans of various implementing ministries, organizations, regional bureaus, development institutions, civil society and the private sector. Therefore, it can show how the policy is formulated to be implemented with the integration of various stakeholders. In contrary to this I found the policy ignoring to discuss the importance and inclusion of youth participation in decision-making process of the policy implementation.

\subsubsection{Financing Method}

Most social policies and programs cannot carry out their function without a source of funding. The greatest ideas for ameliorating social problems will fail if there are not appropriate funding streams in place to bring them to reality (Chambers \& Bonk, 2013).

Considering this nothing is mentioned in the policy document about the source of funding to carry out the policy function.

\section{Part I:}

\subsection{Analysis of Ethiopian Youth Policy Implementation}

Key informant interviews were conducted to come up with qualitative data, which are important to analyze implementation process of the policy. Along with this, the collected data is organized according to themes emerged from the Copeland and Wexler's implementation analysis framework. To this effect, the analysis focuses on themes such as enabling legislation and regulations, organizational structure, organizational process, and program performance.

\subsubsection{Enabling Legislation and Regulations}

Drafting federal legislation is one of the crucial elements of the social policy that connect it to its intended goals. The way federal legislation is drafted can affect the extent to which public policy objectives are attained (Magill, 1984; Mazmanian \& Sabatier, 1983; Nakamura \& Smallwood, 1980; Palumbo \& Harder, 1981; Van Meter \& Van Horn, 1975 cited in Copeland and Wexler (1995)).

Regulations further clarify the benefits to be provided, define the target population, and specify eligibility criteria and administrative authority. They also identify areas of federal involvement such as technical assistance provision, plan and program reviews, evaluations, and audits (Copeland and Wexler, 1995).

In line with this, key informant from head office has described how enabling legislation and regulation is going to be embedded in the national youth policy of Ethiopia.

The NYPE allow the state to practice the role of coordinating and building capacity of executive bodies and youth organizations in a bid to efficiently implement the policy, and the youth development and growth strategy designed to ensure economic, social and political participation of the youth. In this regard, the government should capacitate relevant executive bodies, particularly development-oriented institutions, to allocate the necessary budget and 
integrate the youth development and growth strategy to their respective plans, projects and programs.

\subsubsection{Organizational Structure}

Implementation also depends on the availability of skilled and reliable individuals who can manage the whole process of implementation. Every policy has its intended goals and objectives, which are followed by a strategic action for achieving them. If structures on the ground do not correspond to design, then they are doomed to failure. (Weimer \& Vining, 2005).

Implementation of the NYPE is the responsibility of the Ministry of Women, Children, and Youth Centre. Hence, recognizing the indispensability of an entity that would facilitate implementation of the policy in a coordinated manner, a national coordination committee, run by senior political leadership, was established through proclamation.

In addition, a technical committee, with its own area of responsibility, will be organized under the national coordination committee.

Likewise, an organization that follows the structural framework of the national coordination and technical committees will be organized in regions, city administrations and at all administrative levels.

The organizations in regions, city administrations and other administrative levels will be organized based on the number and composition of members of the national coordination and technical committees. These organizations may incorporate additional members based on the context and situation in their respective areas.

With regard to the organization and activities of the coordination committee, a separate and independent structure will be designed and implemented.

\subsubsection{Organizational Process}

Inter-organizational procedures such as communications, administrative distance, and administrative complexity have an effect on the bureaucratic structure and thereby influence the functional procedures of policy implementation. As Palumbo and Harder (1981) point out, policies are implemented to produce as little interference as possible within the existing structure of the implementing organization.

There are key factors affecting how organization is functioning. These are the internal decision-making structure of the organization; the degree of reliance placed on intermediaries; the degree of interference caused by the innovation; the degree of resistance to change in organizational procedures; and the number of officials from different organizational levels who are engaged in the implementation process (Sosin, 1990; Van Meter \& Van Horn, 1975).

After taking a critical look at the structures of the organization, it is clear that most decisions and related work follow the top-down model of implementation, although some networks on the ground indicate the bottomup approach. The top-down model entails a specific chain of action and behavior that links a policy to desired outcomes, by means of scenario writing that explain what is to be done and by whom (Wiemer \& Vining, 2005). This is a hierarchical approach; authority is held in higher level personnel and restricted to junior staff. The authoritative action comprises of orders from above.

In this model, resource provision and content of the policy are all controlled from the top-down to streetlevel bureaucrats implementing government policies, or organizational staff implementing different programs.

Since the direction of implementing the policy at any level comes from the head office and by simply looking at the above mentioned dominant communication pattern of the organization, one can infer the internal decision making of the organization, is predominantly centralized.

\subsubsection{Program Performance}

The policy was launched, under the Ministry of Women, Children and Youth with implementing different programs, aimed at enhancing the situation of youth in economic, social, and political domain. Based on the identified policy priority areas of action (i.e. Economic Development, Social Aspect, and Political and Civic Participation), program performance analysis in the domain of the Policy is done.

The program performance evaluation is a form of evaluation designed to describe what is going on in the programs, how a programs are operating to and assess how well it performs its intended function to achieve policy objectives (Rossi, Lipsey \& Freeman, 1999).

\subsubsection{Economic Empowerment of Youth}

Some of the objectives of the Policy are concerned on job creation and increasing entrepreneurship development program and skills development of young people. This is precisely what the implementing programs are undertaking. Since the programs started, success has been achieved in profiling and uplifting youth-related activities at both National and Zonal level (i.e. Central Gondar Zone).

According to a performance report from the Ministry of Women, Children, \& Youth (2017/18), the youth are developing an encouraging culture of saving. An incremental trend is showing and a total amount of $4,582,540,185$ birr were saved by the youth.

The number of youths who can able to access credit in the past three years can also be found in the below table. 
Table 5: Number of Youth who accessed a Credit Service for the Years 2015/16-2017/18

\begin{tabular}{lllll}
\hline Year & Total & Male & Female & $\begin{array}{l}\text { Amount of loan } \\
\text { provided in birr }\end{array}$ \\
\hline $2015 / 16$ & $2,165,017$ & $2,983,510$ & $1,734,694$ & $1,462,390,725$ \\
$2016 / 17$ & $1,356,475$ & $1,790,106$ & $1,132,800$ & $6,315,187,078.97$ \\
$2017 / 18$ & 808,542 & $1,193,404$ & 601,894 & $5,745,836,000$ \\
\hline
\end{tabular}

Source: Adolescent and Youth Status Report, 2018.

As part of the interventions to raise economic empowerment of youth, the government of Ethiopia had also initiated the youth revolving fund to make available the financial resources needed to enable youth to realize their productive potential and become direct participants in economic activities. The total amount of funds distributed for youth empowerment is 10 billion birr, out of which 9.01 billion birr were released as of December 2018. The table below presents the most recent performance of the Youth Revolving Fund.

Table 6: Released amount of the youth revolving fund by region (2017-18)

\begin{tabular}{rllll}
\hline S/N & Region & Allocated budget & Released amount (birr) & Remaining balance \\
\hline 1. & Oromia & $3,440,847,609.90$ & $3,096,766,853.96$ & $344,080,756$ \\
2. & SNNPRS & $1,882,000,000.00$ & $1,882,000,000.00$ & 0 \\
3. & Amhara & $2,677,069,826.33$ & $2,677,069,826.33$ & 0 \\
4. & Tigray & $526,576,349.21$ & $315,945,809.51$ & $210,630,539.60$ \\
5. & Addis Ababa & $419,000,000.00$ & $419,000,000.00$ & 0 \\
6. & Dire Dawa & $54,964,717.21$ & $43,971,773.61$ & $10,992,943.60$ \\
7. & Harari & $26,774,457.93$ & $26,774,457.93$ & 0 \\
8. & Benishangul-Gumuz & $112,901,483.01$ & $79,031,037.51$ & $33,870,445.50$ \\
9. & Gambella & $50,178,214.50$ & $35,124,751.80$ & $15,053,462.70$ \\
10. & Somali & $602,662,660.57$ & $361,597,596.37$ & $241,065,064.20$ \\
11. & Afar & $206,441,115.48$ & $82,576,446.18$ & $123,864,669.30$ \\
Total & & $10,000,000,000$ & $9,019,858,553$ & $980,141,447$ \\
\hline
\end{tabular}

Source: Adolescent and Youth Status Report, 2018.

The above mentioned data is substantiated by data gained from key informant at central Gondar zonal office and mentioned as follows:

In the past, it was very difficult for young people to access funds for starting their businesses because the majority of banks criteria are very rigid. Most young people, especially from lower class family background, since they do not have collaterals (assets to be used for guarantee); it was very difficult for them to access finance. With the coming of provident fund and differentsaving and credit associations, the requirements to get access to loan services for youth has become somewhat an easy task.

Therefore, from the above-mentioned data we can understand that making accessible loan service to youth and the youth revolving fund has been accelerating business and production capacity of youth in the country generally and Central Gondar Zone specifically. Hence, it enhances economic benefit of youth.

By recognizing the fact that the burning economic issue of the youth is unemployment and with the intention of addressing this problem, several works have been undertaken to engage large numbers of the youth in rural and urban areas in agricultural and non-agricultural sectors. From these sectors, youths were participating in crop production, horticulture development, apiary development, supply of construction materials, small-scale businesses, urban housing development and construction programs, industrial and trade sectors, urban farming and private economy. This has enabled a large number of the youth to make wealth and saving.

Efforts have also been exerted to change the poor work culture of the youth and enhance their capacity, and address attitudinal problems on the part of the society and stakeholders thereby bring about national consensus in the development of this sector. In addition to the establishment of a Job Creating Task Force or Agency with an intention of addressing the problem of unemployment, works have been done that enabled to create job opportunities for millions of youth and enhance their benefits through the establishment of relevant service rendering center to economic development engines. Efforts have also been exerted to ensure the participation and benefits of the youth in rural areas, though it was unable to execute this activity in a sustainable and uniform way (Adolescent and Youth Status Report, 2018).

To enhance the employability of youth at zonal level, the Central Gondar Zonal bureau is trying to identify and register unemployed youth at Kebele, Wereda and Zonal levels. Hence, it helps to find out compatible employing opportunities for the needy youth. Key informant at central Gondar zone has mentioned the necessity of identifying unemployed youth as follows:

First, when the youth come, they are assessed to check whether they are employed or not. If they are not employed, they are going to be registered as unemployed youth based on the level and educational qualification. Then, when the compatible employment opportunity comes they 
will immediately be informed to compete and get employed.

Furthermore, industrial parks in Ethiopia have contributed significantly to the nation's industrial development in terms of creating employment, increasing government revenue and export, diversifying the industrial products, attracting Foreign Direct Investment, and attracting foreign exchange. Based on an annual growth rate of at least 11 percent in the forthcoming years, industrial parks are expected to create 32,000 new jobs in manufacturing, mostly targeting younger Ethiopians. Besides, availability of compiled and disaggregated data by age regarding employment opportunities in government mega projects was scarce, employment opportunities created by investment projects are captured and organized by the Ethiopian Investment Commission, but the data is not disaggregated by age and place. However, it is assumed by the officials of the commission that most of the employment opportunities created by the investment projects are youth based (Adolescent and Youth Status Report, 2018).

As key informant from federal office has mentioned:

Despite the encouraging results gained in the areas of employment opportunity creation in particular and enterprise development, implementation capacity and other limitations detected around youth organizational structures, the society and the government have become stumbling blocks for attaining the intended development goals and have prohibited the youth from enjoying benefits from economic development achievements.

Having mentioned this, the informant has further attributed:

The failure to provide adequate industrial extension services to youth movements in urban areas which by themselves failed to consider the needs of the youth, the absence of effective, efficient and uniform service provision center, the inability of providing skill and entrepreneurship training, insufficient technology supply, the failure to apply Kaizen philosophy, the limited availability of working and selling places, and failure to pass these places to users on timely basis, the absence of adequate loan provision services and of transaction opportunities were the major impediments for the development of the youth. Moreover, the dependency and get-rich-quick attitude of the youth and their obsession to go to abroad were also additional challenges that were witnessed in this area.

\subsubsection{Improving Social Status of Youth}

Social problems are major challenges preventing the youth from participating in the all-round national development and growth. Through the extensive activities undertaken with the popular participation of the government and stakeholders to tackle the challenges encountered in this regard, encouraging results have been achieved.

In order to enhance the participation and benefits of the youth in and from education development, the government has exerted exhaustive efforts. Such as, in the areas of the expansion of schools, building of vocational and technical institutions, designing and application of adult education facilities that enables adult population to get access to education in their own surrounding.

According to Adolescent and Youth Status Report (2018), youth literacy rate refers to the percentage of people aged 15 to 24 years who can both read and write with understanding a short simple statement on their everyday life. In line with this, the youth literacy rate has shown a tremendous change over the last two decades as compared with $33.6 \%$ in 1994 to $69.3 \%$ in 2015 . The proportion of literate female youth has also improved, and the gender gap has narrowed.

Moreover, the government of FDRE has designed and applied into practice an education certification package in order to ensure the quality of education. It has also created situations conducive for investors to involve in the expansion of education facilities extensively benefiting several numbers of young people from accessing education and employment opportunities.

As key informant from federal office mentioned:

Encouraging results have also been achieved in the provision of primary education to all citizens thanks to the extensive activities made in this regard. However, the rural community has not been adequately reached with secondary and integrated adult education services. Limitation has also been detected in the area of ensuring education quality and produce skilled educational professionals as required.

In the health sector, several initiatives have been undertaken in Ethiopia over the last decades culminating in the launching of the National Adolescent and Youth Reproductive Health Strategy (AYRH) in 2006. The nine year (2007-2015) National AYRH Strategy sought to provide a multi-sectoral support to every young person living in Ethiopia with education and information that will lead to adoption of a healthy lifestyle physically, psychologically, and socially. This was to be achieved through provision of age and sex appropriate information and counseling, comprehensive health services complemented by self-care, as well as livelihood and leadership skills.

It has also developed and implemented a 5 year National Adolescent and Youth Strategy from 2016 to 2020 
to increase access and use of quality reproductive health service (FMOH, 2016). The strategy encouraged adolescents and youth to utilize available health services, to some extent, which in turn improved the environment for implementation of Adolescent and Youth Sexual and Reproductive Health (AYSRH) programs and services in the country $(\mathrm{FMOH}, 2016)$. However, various challenges were faced during the implementation of the strategy such as limitations in the scope of the strategy, lack of coordination among implementing partners, low stakeholder and youth involvement, inadequate resources, and social and cultural barriers to the services (FMOH, 2016).

One of the major activities undertaken to curb the social problems that young people face was the prevention of illegal migration and human trafficking. A National Taskforce in charge of preventing illegal migration and human trafficking was set up and is providing legal protection to victims of these illicit practices. The government, by taking the prevention of human trafficking and illegal immigration as its main agenda and with the objective of addressing these problems, has carried out extensive activities to make the public well aware of the problems through various forums and Medias.

The other work undertaken in the social sector was the expansion of youth development and youth recreational centers enabling the youth to get access to these services. Encouraging results have been achieved in the area of producing physically fit, healthy and productive citizens thanks to the extensive activities undertaken in this regard.

\subsubsection{Civic and Political Participation of Youth}

The numbers of young people involving in voluntary services have grown remarkably. Thanks to the introduction of youth voluntary program in the country with an intention of increasing the participation of the youth in social services and enhance their capacity in shouldering social responsibility.

Youth volunteerism is being promoted and coordinated by the government of Ethiopia particularly the Ministry of Women, Children, and Youth by mobilizing adolescents and youth in both the summer and winter schedules starting from 2004. Furthermore, cross boundary youth service programs that allow youth volunteers from one region/city administration to serve community service activities in another region/community. This program mainly targets the enhancement of peace building, building a sense of patriotism, and fostering social cohesion among youth volunteers as well as sharing of cultures and experiences from another locality that they did not know previously. This program is gaining a strong momentum and leadership among high-level government officials. In addition, the youth/adolescents that were involved in cross boundary volunteer service programs were 120 in 2016/17 and scaled up to 1000 volunteer youths in 2017/18 (Adolescent and Youth Status Report, 2018).

The 1995 FDRE constitution allows for a free and fair election and admittedly, the youth came out in large numbers to take part in the events in the past. However, there is limitation of information on the number of youth voters and their degree of engagement in the overall process of national elections; it is evident that the youth played a big role in these elections mainly as voters if not as contestants. The youth accordingly took noteworthy roles as both observer and implementer of elections. Besides, 15,000 youth were deployed as observers in the most recent election that took place in 2014/15 (Adolescent and Youth Status Report, 2018).

\section{Discussion and Conclusion}

The ultimate goal of this study was to uncover the policy formulation and implementation process of Ethiopian youth police. Analysis of the policy implementation process was conducted at both the National and Central Gondar zone.

To this end, the study set out to investigate the following specific objectives: on the one hand, in policy formulation analysis, the study seek to critically evaluate all parts of a policy and how they fit together as a whole, with the ultimate purpose to make judgments on the goodness, fitness, and appropriateness of a given policy. On the other hand, in policy implementation analysis, the study intends to explain the implementation process, examine the extent to which programmatic goals were satisfied, and describe how well the policy performed.

To this effect, the study has employed document analysis for investigating the nature of a policy document in order to look at both what lies behind it and within it. Moreover, the study has employed document analysis along with key informant interviews to analyze the policy implementation process at both country level and Central Gondar zone. Besides, the study has employed two different types of analytical framework to address central issues of the study. On the one hand, Value Critical Policy Analysis Framework was employed to analyze the policy formulation process. On the other hand, Copeland and Wexler (1995) Implementation Analysis Framework was employed to analyse the policy implementation process.

Regarding the policy formulation analysis the policy document has markedly state social problem, situation of youths, and intended objectives of the policy in both measureable and flexible way. However, the policy document has failed to state vision and goal of the policy in reference to time parameter as to when to achieve the stated vision and goal of the policy. Considering the issue of cost effectiveness, fitness to the social problem 
analysis, and its implication to the issue of adequacy, equity and efficiency, the policy is designed to be implemented at different level (i.e. federal, regional, zonal, and kebele level). Hence, the issue of cost effectiveness, adequacy, equity and efficiency could be managed and secured at best.

Moreover, the policy document has clearly specified which segment of the population has to be considered in the policy without stigmatizing and favored to any groups. With this regard, the study has found the policy document as securing its entitlement rules as adequate and efficient.

The policy document has clearly showed the importance of stakeholder's involvement in the process of policy implementation. Yet, the policy has ignored to discuss the importance and inclusion of youth participation in decision making process of the policy implementation. However, it is known that social policies and programs cannot carry out their function without a source of funding; nothing is mentioned in the policy document about the source of funding to carry out the policy function.

In order to address the stated objectives in the policy document, the government of Ethiopia has made different activities in collaboration with different stakeholders. To this end, the implementation process of the policy was conducted based on Copeland and Wexler (1995) analysis framework, so that inferences can be made about the relationship between policy design, policy implementation, and policy outcome. Moreover, the analysis focuses on themes such as enabling legislation and regulations, organizational structure, organizational process, and program performance.

The results of the study on the implementation analysis of the policy indicate that elements of implementation of the National Youth Policy (2004) are occurring, but with some challenges. One of the guiding principles of the National Youth Policy of Ethiopia, that connects it to intended goals of the policy, is to establish youth structures at local level, meaning in all regional, zonal, wereda, and kebele levels. The implementation process of National Youth Policy of Ethiopia cannot take place if there are no realistic social structures in the above-mentioned levels.

The National Youth Policy of Ethiopia was driven towards a holistic approach to youth development. Most activities pertain to economic and carrier development focusing on entrepreneurship. The policy is being implemented mainly through the top-down model. Through this model, most decisions come from the top, from the head office in Addis Ababa, through the regional office, to the zones, weredas, kebeles.

Economic developments of the youth are designed to increase entrepreneurial culture, business managerial capacities, technical skills and talents among young people, thereby contributing to sustainable human development of the target groups. This is being done through the provisions of loans, offering business skills such as bookkeeping and linking the youth with other established businesses in their environment. It is hoped that youth business ownership will grow to a level at which fellow youths with vibrant business and successful entrepreneurs will be able to plough resources back into youth development.

However, as emerged from the study, one of the major challenges faced in the implementation of the policy is loan defaults. This is due to lack of business skills relevant to the market needs and lack of an entrepreneur culture among the youth. It is difficult for young people to excel in their business adventures when faced with stiff competition with experienced business groups in the municipalities. This calls for a strong partnership between the zonal youth bureau and the private sector. The private sector, which is mainly the driving force behind economic activities and business enterprises in the city, should be fully involved in the quest of youth development. Without the private sector, efforts to uplift the youth will be hard.

One of the areas of intervention is to increase savings and investment among youth through encouraging them to establish co-operative enterprises and other forms of enterprises. These co-operatives can be successful if the youth work together with experienced business corporations in the city. Breaking the cycle of poverty, unemployment and squalor and increasing business opportunities for youth to participate fully and meaningfully in the economic landscape, remains a challenge for Ethiopia. This cycle can be broken if different stakeholders at different levels are willing to be involved in the development of youth status. This should not be the work of the government alone. If it is, all efforts will fail.

Moreover, in order to enhance the participation and benefits of the youth in and from education development, the government has exerted exhaustive efforts. Like, in the areas of the expansion of schools, building of vocational and technical institutions, in designing and application of adult education facilities that enable the adult population to get access to education within their surroundings. However, the rural community has not been adequately reached with secondary and integrated adult education services.

Besides, many things have been done to promote the health status of youth including the construction of recreational centers. However, as a result of limitation in the standards of recreational centers (which are not well equipped with the required materials), and lack of appropriate infrastructures to the centers, compared to their contribution in making the youth to be healthy and physically fit, they may expose young people to become victims of bad habits and social evils.

Furthermore, remarkably acknowledgeable efforts were done in the introduction of youth voluntary program in the country with an intention of increasing the participation of the youth in social services and 
enhance their capacity in shouldering social responsibility. Besides, the emerging effort has been done to promote youth participation on politics.

\section{Recommendation}

The recommendations forwarded below are meant to draw attention of policy makers on main youth issues and only to inform on the areas that need decision and action. The researcher has suggest the following policy level recommendations to be considered in the future.

$>$ The mentioned age category to be considered as youth in the policy should be revised in compatible with the country's development level and the African Youth Charter.

$>$ The policy document has to point out and include youths and illegal human trafficking as one of the policy direction.

$>$ Since traffic accident is one of the leading evils attacking youths of the country, activities that can minimize incidence of traffic accident should be stated on the policy document.

$>$ The policy should clearly state conditions by which the most disadvantage youths (for instance, women and disabled youths) could be benefited.

$>$ The youth policy and related youth focused implementation strategies requires to be assessed for potential improvement in line with the newly unfolding paradigm shifts at the national level and the demands of the youth. Besides, youth issues and perspectives must be taken on board in the assessment and revision of the youth policy, strategies, and packages.

> Regarding with promoting economic status of youth, the policy must point out a careful sketch of youth profile on the labor market, the main barriers for youth employment, and the socio-economic challenges of youth. Furthermore, utilization of the youth revolving fund needs a deep study to overcome the enormous shortcoming in administration of the fund.

> With regards to social services, a much more focused leadership must be given for youth health promoting right based family planning, mental health care, and youth friendly services. Moreover, the education system and training programs need to be revisited to produce skills much needed by the labor market.

$>$ In addition due attention need be given on the root causes as to why youth centers largely became dysfunctional with the aim of taking appropriate solution measures. Besides, the centers must be made female friendly.

$>$ Youths and volunteerism should be identified and included in the policy document as one of the policy direction. Therefore, youth volunteer services (internships, campaigns, school scout members, and club members) must be vigorously fostered and scaled up.

$>$ With regard to, civic and political participation, there is a need for mobilization of fragmented youth power and to reorient the youth on the virtues of nationalism, patriotism, and ethical values to cherish and upload the merits of serving society and the country. Furthermore, a workable strategy must be devised to enhance youth participation in elections both as voters and representatives. Fixing quotas for the youth in constituencies at national and regional levels need be considered.

$>$ Though the policy document has mentioned to design systems to follow up and evaluate the policy implementation process, it failed to mention who is responsible to design the system and how the system tends to monitor the implementation process of the policy accountably. The policy must devise an effective mechanism that enables to effectively monitor, evaluate, and report the implementation process with mentioning who and how the actors are accountable.

\section{Reference}

Carr Copeland, Valire and Wexler, Sandra. (1995). Policy Implementation in Social Welfare: A Framework for Analysis. The Journal of Sociology \& Social Welfare: Vol. 22 : Iss. 3 , Article 4.

Chambers, D.E. \& Bonk, J.F. (2013). Social policy and social programs: A method for the practical public policy analyst (6th ed.). Boston, MA: Pearson Education, Inc.

Donald S. Van Meter, and Carl E. Van Horn. (1975). The Policy Implementation Process: A Conceptual Framework. Sage publications, inc.

Donald E. Chambers and Kenneth C. Wedel. (2005). Social Policy and Social Programs: A Method For The Practical Public Policy Analyst, $4^{\text {th }}$ Edition.

Federal Democratic Republic of Ethiopia. (1995). Constitution of the Federal Democratic Republic of Ethiopia. Addis Ababa, Ethiopia.

Federal Democratic Republic of Ethiopia, Ministry of Health (FMOH). (2006). National Adolescent and Youth Health Strategy (2016 to 2020). Addis Ababa, Ethiopia.

Federal Democratic Republic of Ethiopia, Ministry of Health (FMOH). (2006). National Adolescent and Youth Reproductive Health Strategy (2007 to 2015). Addis Ababa, Ethiopia. 
Federal Democratic Republic of Ethiopia, Ministry of Sports, Youth and Culture. (2004). National Youth Policy.

Federal Democratic Republic of Ethiopia, Ministry of Women, Children, \& Youth. (2018). Adolescent and Youth Status Report.

Mazmanian, D. A., \& Sabatier, P. A. (1983).Implementation and public policy. Glenview, IL: Scott, Foresman and Company.

Neil Gilbert and Paul Terrell. (2010). Dimensions of Social Welfare Policy. $7^{\text {th }}$ edition. Allyn \& Bacon publisher.

Palumbo, D., \&Harder, M. (1981).Implementing public policy. Lexington, MA: Lexington Books. Rein (1995)

Rossi PH, Freeman HE, Lipsey MW. (1999). Evaluation: A Systematic Approach. Thousand Oaks, CA: Sage. 500 pp. 6th ed

Sosin, M. R. (1990). Decentralizing the social service system: Areassessment. Social Service Review, 64, $617-$ 636.

United Nations Economic Commission for Africa. (2009). African Youth Report: Expanding Opportunities for and with People in Africa. Addis Ababa.

United Nations Population Fund. (2013). Strategy on Adolescents and Youth: Towards realizing the full potential of adolescents and youth.

Weimer, David L and Vining Aidan. 2005. Policy Analysis: Concepts and Practices, New Jersey: Upper Saddle River. Prentice Hall. 